\title{
Effects of Hydrogen Sulfide Synthesis Inhibitors on Posthypoxic Ventilatory Behavior in the C57BL/6J Mouse
}

\author{
Lucas M. Donovan $^{a}$ Michael W. Moore ${ }^{b, c}$ Carl B. Gillombardo ${ }^{b, c}$ Sam Chai ${ }^{b, c}$ \\ Kingman P. Strohl ${ }^{b, c}$ \\ ${ }^{a}$ Case Western Reserve University School of Medicine, ${ }^{b}$ Department of Pulmonary, Critical Care and Sleep \\ Medicine, Case Western Reserve University, and ' Louis Stokes VA Medical Center, Cleveland, Ohio, USA
}

\section{Key Words}

Hypoxia $\cdot$ Respiratory control $\cdot$ Apnea $\cdot$ Hydrogen sulfide

\begin{abstract}
Background: $\mathrm{H}_{2} \mathrm{~S}$ synthesis inhibitors (HSSI) have been shown to impact respiratory control. For instance, the HSSI hydroxylamine $(\mathrm{HA})$ decreases the respiratory discharge rate from isolated medullary sections, and $\mathrm{HA}$ in addition to other HSSIs propargylglycine and amino-oxyacetic acid (AOAA) have been found to reduce hypoxic responsiveness. Objectives: The aim of this study was to determine if administration of HSSls could improve respiratory stability in an intact organism prone to recurrent central apneas. Methods: Saline and HSSI compounds were administered to C57BL/6J mice $(n=24)$, a strain predisposed to recurrent central apneas, prior to measurement of hypoxic and posthypoxic ventilatory behavior. Results: Administration of HA and AOAA resulted in a significantly smaller percentage of animals expressing one or more apneas during reoxygenation compared to saline control, and animals given AOAA demonstrated a smaller coefficient of variation for frequency during reoxygenation, a marker suggesting greater respiratory stability. This occurred despite varying effects of the three HSSI compounds on hypoxic ventilatory response. Conclusions: Instability and pause expression are improved by targeting $\mathrm{H}_{2} \mathrm{~S}$ synthesis, an effect not predicted by effects on hypoxic responsiveness.
\end{abstract}

Copyright $\odot 2011$ S. Karger AG, Basel

\section{KARGER}

Fax +4161306 1234

E-Mail karger@karger.ch

www.karger.com (c) 2011 S. Karger AG, Basel

Accessible online at: www.karger.com/res

\section{Introduction}

Hydrogen sulfide $\left(\mathrm{H}_{2} \mathrm{~S}\right)$ is a gaseous chemical messenger which has been implicated in a multitude of physiologic processes. $\mathrm{H}_{2} \mathrm{~S}$ arises from the amino acid cysteine via a reaction catalyzed by cystathionine $\gamma$-lyase (CSE), cystathionine $\beta$-synthase (CBS) and 3-mercaptopyruvate sulfurtransferase $[1,2]$. Recently, $\mathrm{H}_{2} \mathrm{~S}$ activity has been found to be of considerable consequence in carotid body function. Acute administration of the CBS inhibitors hydroxylamine (HA) and amino-oxyacetic acid (AOAA) as well as chronic administration of the CSE inhibitor propargylglycine (PAG) diminish ex vivo carotid body responsiveness to hypoxia and hypercapnia $[3,4]$. Furthermore, a blunted hypoxic responsiveness occurs in vivo in Kunming mice administered HA and AOAA [3] as well as mice with knockout mutations for CSE [4]. In addition, the discharge rate of rhythmic respiratory activity in isolated medullary sections from neonatal rats will decrease in response to HA and increase with administration of the CBS substrate cysteine, suggesting a potential role for $\mathrm{H}_{2} \mathrm{~S}$ signaling in central respiratory control [5]. These observations imply that the pathways influencing $\mathrm{H}_{2} \mathrm{~S}$ synthesis and activity could be targets of drug therapy for disorders of ventilatory control including unstable breathing disorders seen in a variety of medical and neurologic conditions [6].

\footnotetext{
Kingman P. Strohl

Louis Stokes Cleveland VA Medical Center

Medical Research/K-215

Cleveland, OH 44106 (USA)

Tel. +1 216402 1453, E-Mail kpstrohl@aol.com
} 
The C57BL/6J (B6) strain of mouse exhibits unstable breathing marked by recurrent apneas and an increased coefficient of variation (CV) for breath to breath respiratory frequency; this behavior is particularly prominent in the reoxygenation period following hypoxic exposure [7]. Posthypoxic instability in the B6 improves following administration of the carbonic anhydrase inhibitor acetazolamide and the serotonin $5-\mathrm{HT}_{1 \mathrm{~A}}$ partial agonist buspirone $[8,9]$. In these studies and in those involving genetic manipulations, a relationship between chemoresponsiveness and apnea presence cannot be inferred by direct comparisons.

In the current study, we attempt to elucidate whether administration of hydrogen sulfide synthesis inhibitors (HSSI) will result in alterations in the posthypoxic respiratory instability of the $\mathrm{B} 6$ mouse. We anticipated that an attenuation of respiratory responsiveness to hypoxia will reduce the propensity for posthypoxic respiratory instability, implying a reducing effect on loop gain $[10$, 11 .

\section{Materials and Methods}

\section{Animals}

Experiments were performed on 10-week-old male C57BL/6J mice ( $\mathrm{n}=24$; Jackson Laboratory). Animals were housed at the Louis Stokes Veterans Affairs Medical Center Animal Research Facility for 1 week prior to testing (food and water ad libitum; 12:12-hour consistent light-dark cycle). The protocol was approved by the Louis Stokes Veterans Affairs Medical Center Animal Care and Use Committee and is consistent with the National Institutes of Health's Guide for the Care and Use of Laboratory Animals.

\section{Experimental Protocol}

The mice were divided into groups of 6 animals. Ventilatory behavior in each group was first measured following intraperitoneal (i.p.) saline injection, and 3 days later ventilatory behavior was measured following i.p. administration of a HSSI which was different for each group of 6 animals. The HSSI consisted of either HA (300 $\mu \mathrm{mol} / \mathrm{kg}$; Sigma), HA (600 $\mu \mathrm{mol} / \mathrm{kg}$; Sigma), AOAA (300 $\mu \mathrm{mol} / \mathrm{kg}$; Sigma), or PAG $(1,800 \mu \mathrm{mol} / \mathrm{kg}$; Sigma). Note that this study uses a dose of HA at $600 \mu \mathrm{mol} / \mathrm{kg}$ which is higher than that previously used [3]. This was done due to enhanced effects on reducing apneic activity noted during preliminary testing.

Ventilatory behavior was tested via whole body plethysmography using an apparatus which has been used and described previously by this laboratory $[7,8,12]$. To minimize effects of circadian rhythm, testing was performed between 10 a.m. and 2 p.m. Animals were placed in the plethsymography chamber for a 45-min acclimatization period, and at the end of this period, rectal temperatures were obtained and animals received an i.p. injection of either saline or one of the HSSI formulations. Following this in- jection, the animals experienced another 15-min acclimatization period. Baseline breathing was measured for $1 \mathrm{~min}$ at the end of acclimatization followed by a 5 -min hypoxic challenge with poikilocapnic gas $\left(8 \% \mathrm{O}_{2}\right.$, bal- $\left.\mathrm{N}_{2}\right)$. The hypoxic challenge was then followed by a 5 -min reoxygenation period with $100 \% \mathrm{O}_{2}$. Rectal temperatures were also obtained following the reoxygenation period. Rectal temperatures were not performed during the hypoxic or reoxygenation periods so as to avoid disruption of ventilatory behavior.

\section{Analysis of Respiratory Data}

The plethysmography data were analyzed using a program custom written for our lab (Breath Detect) which was created to be compatible with data obtained in Lab View 9.0 (National Instruments). Data were scored from continuous recordings over 60 -second time periods in the first and fifth minutes of each challenge and the $1 \mathrm{~min}$ of resting breathing following acclimation. Sniffs and sighs were excluded from analysis.

At rest and for each challenge, the values of frequency $(f)$, tidal volume $\left(\mathrm{V}_{\mathrm{T}}\right)$, and minute ventilation $\left(\mathrm{V}_{\mathrm{E}}\right)$ (with $\mathrm{V}_{\mathrm{T}}$ and $\mathrm{V}_{\mathrm{E}}$ normalized for weight) were compared between saline and each HSSI group. To investigate for short-term potentiation (STP) and posthypoxic frequency decline (PHFD), baseline $f$ was compared to the $f$ seen during the first minute of reoxygenation. The primary endpoint of our study was the presence or absence of one or more apneas during the first minute of reoxygenation, with apneas being defined as an absence of breathing activity, as measured by plethysmography, lasting longer than two breaths. The CV for respiratory frequency has been used previously as a marker of respiratory stability in rodents [13-15] and was calculated for each animal at rest and during the posthypoxic/reoxygenation period. $\mathrm{CV}$ and the presence or absence of apneic episodes were compared between saline and each HSSI group.

To assess the effect of HSSI administration on body temperature, pretesting (pre-injection) and posttesting rectal temperatures were compared between each HSSI administration and saline. Pre- and posttesting temperatures were also compared to each other within groups. Chamber temperature remained constant at $21.8 \pm 0.1^{\circ} \mathrm{C}$.

In order to assess the effects of HSSI administration on body temperature, independent of changes in environmental oxygen, rectal temperatures were taken in age-matched B6 mice who were not tested in the plethysmography chamber ( $n=3$ per group). Rectal temperatures were obtained prior to injection, and at 1, 5, 10, 20 and 30 min following i.p. injection. Postinjection rectal temperatures in HSSI groups and saline were compared to preinjection temperature within groups, and postinjection temperatures in HSSI groups were also compared to saline.

\section{Analysis}

In comparing the HSSI and saline groups for postinjection temperature, $\mathrm{CV}, f, \mathrm{~V}_{\mathrm{T}}$ and $\mathrm{V}_{\mathrm{E}}$, one-way ANOVA was used to detect significant differences among groups, and post hoc Dunnett's test compared each group to saline. Comparisons within groups (such as pre- and postintervention temperature, PHFD and STP), were accomplished with a paired t test for means. $\mathrm{Z}$ test for proportions was used to compare the percentage of animals per group expressing one or more apneas. In each analysis, $\mathrm{p}<0.05$ was used as the threshold for significance. Values are expressed as means \pm standard error. 


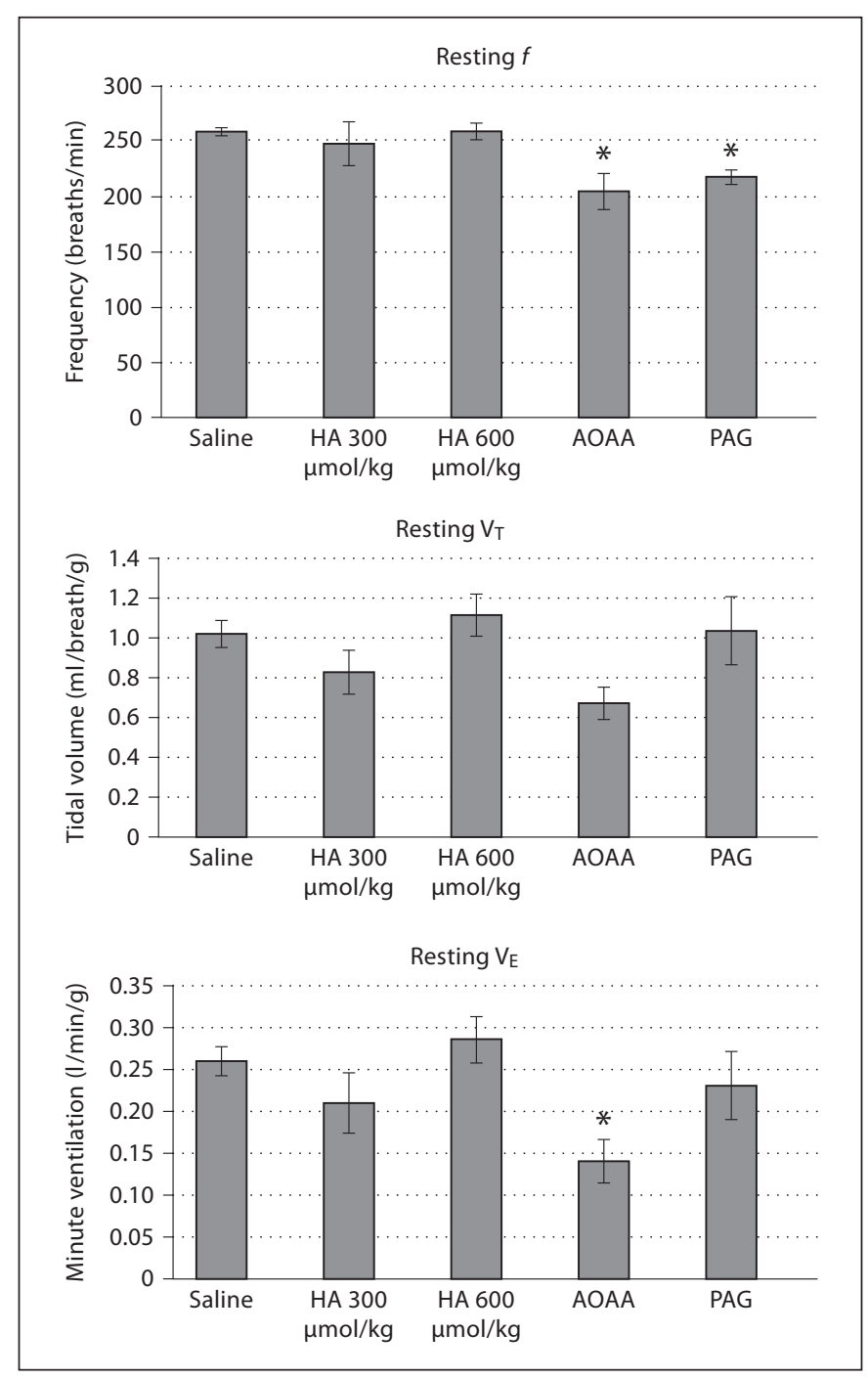

Fig. 1. Ventilatory behavior during resting breathing. $V_{T}$ and $V_{E}$ have been normalized for mass. Injection group was found to significantly impact $f$ and $\mathrm{V}_{\mathrm{E}}$. Significant differences from saline group as determined by Dunnett's test are noted as follows: ${ }^{*} \mathrm{p}<$ 0.05 . Note that as in subsequent figures $n=24$ for saline group and $\mathrm{n}=6$ for each HSSI group.

\section{Results}

\section{$F, T_{V}$, and $V_{E}$ during Rest, Hypoxia and}

\section{Reoxygenation}

At rest, following i.p. injection, $f$ and $\mathrm{V}_{\mathrm{E}}$ were found to vary by injection group. By post hoc analysis, $f$ was significantly lower than saline control in animals receiving PAG and AOAA, and $V_{E}$ was decreased in AOAA (fig. 1). During hypoxia, AOAA resulted in blunted $f, \mathrm{~V}_{\mathrm{T}}$ and $\mathrm{V}_{\mathrm{E}}$ compared to saline (fig. 2). During reoxygenation follow-
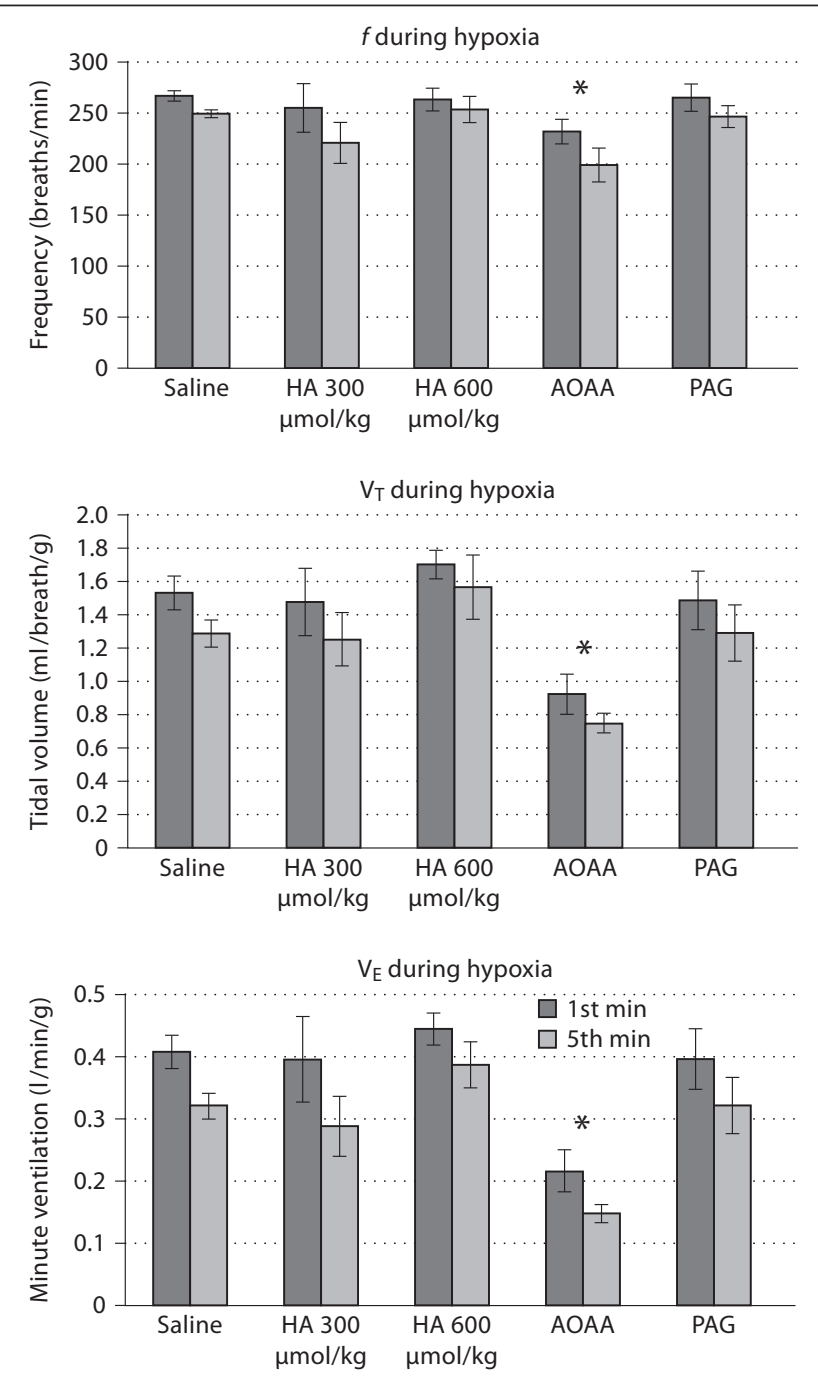

Fig. 2. Ventilatory behavior during hypoxia. $\mathrm{V}_{\mathrm{T}}$ and $\mathrm{V}_{\mathrm{E}}$ have been normalized for mass. For $f, \mathrm{~V}_{\mathrm{T}}{ }^{\prime}$, and $\mathrm{V}_{\mathrm{E}}{ }^{\prime}$, drug administration was found to have a significant effect by ANOVA at $\mathrm{p}<0$. 01. Each group was compared to saline by post hoc Dunnett's test, and significant differences are noted as follows: ${ }^{*} \mathrm{p}<0.05$.

ing hypoxia, AOAA-injected animals again possessed blunted $f, \mathrm{~V}_{\mathrm{T}}$ and $\mathrm{V}_{\mathrm{E}}$ compared to saline (fig. 3).

\section{Resting Respiratory Stability}

Compared to saline administration, no HSSI group experienced a significant difference in the percentage of animals experiencing one or more apneas (fig. 4). Administration group contributed significantly to $\mathrm{CV}$ during resting breathing $(\mathrm{p}<0.01)$, but post hoc Dunnett's test failed to demonstrate any one group which varied sig- 


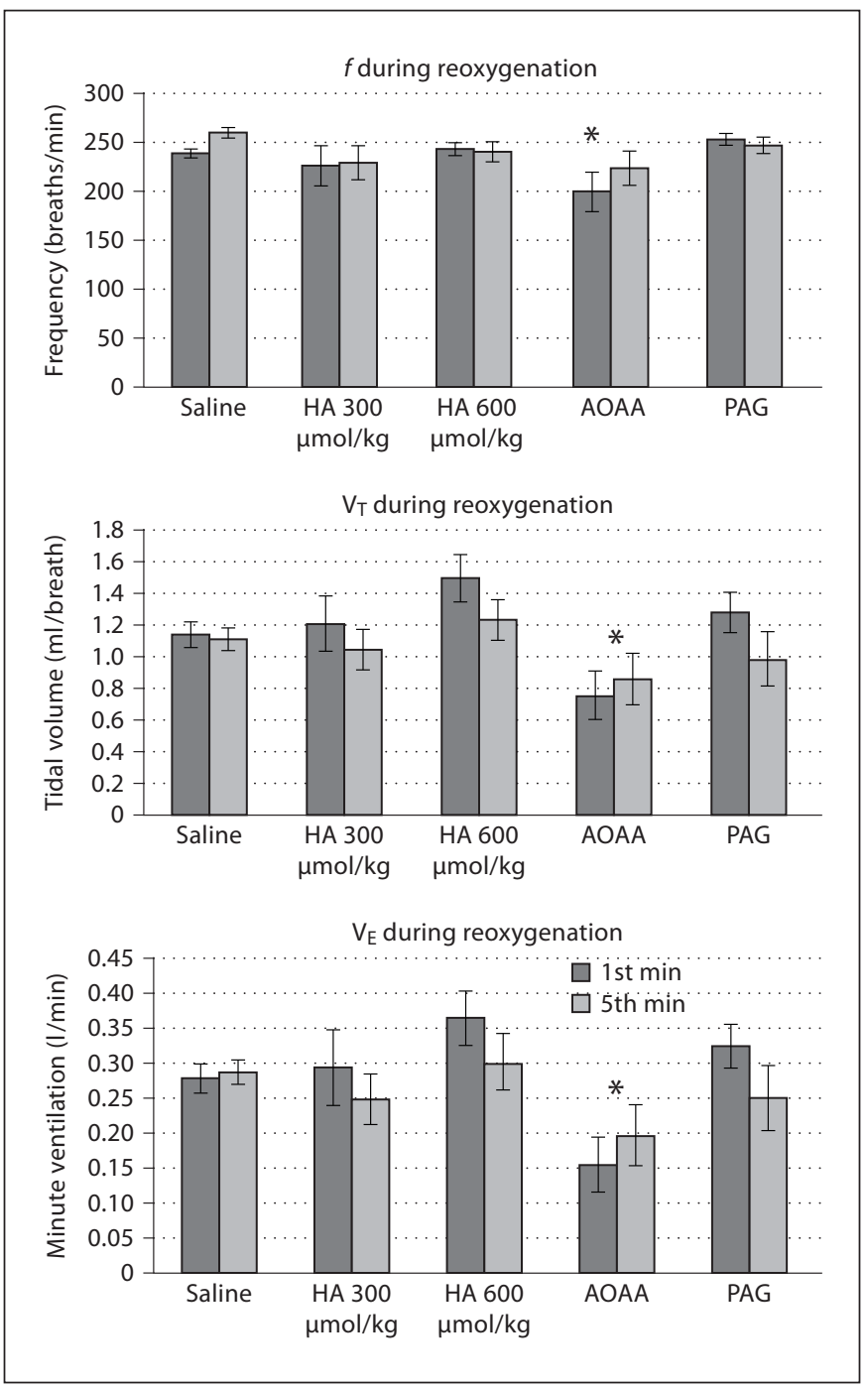

Fig. 3. Ventilatory behavior during reoxygenation following hypoxia. $\mathrm{V}_{\mathrm{T}}$ and $\mathrm{V}_{\mathrm{E}}$ have been normalized for mass. For $f, \mathrm{~V}_{\mathrm{T}}{ }^{\prime}$, and $\mathrm{V}_{\mathrm{E}}{ }^{\prime}$, drug administration was found to have a significant effect by ANOVA at $p<0$. 05. Each group was compared to saline by post hoc Dunnett's test, and significant differences are noted as follows: ${ }^{*} \mathrm{p}<0.05$.

nificantly from saline, although there was a trend towards significance in the HA $(300 \mu \mathrm{mol} / \mathrm{kg})$ group $(\mathrm{Q}=$ 2.517, critical $\mathrm{Q}=2.535)$. The HA $(300 \mu \mathrm{mol} / \mathrm{kg})$ group experienced a lower $\mathrm{CV}$ than saline (fig. 5).

\section{Posthypoxic Respiratory Stability}

Upon comparison of resting and first-minute reoxygenation $f$ by paired t test, saline-administered animals exhibited PHFD, whereas PAG administration resulted in STP (fig. 6).

$\mathrm{H}_{2} \mathrm{~S}$ Synthesis Inhibitors and Respiratory Stability

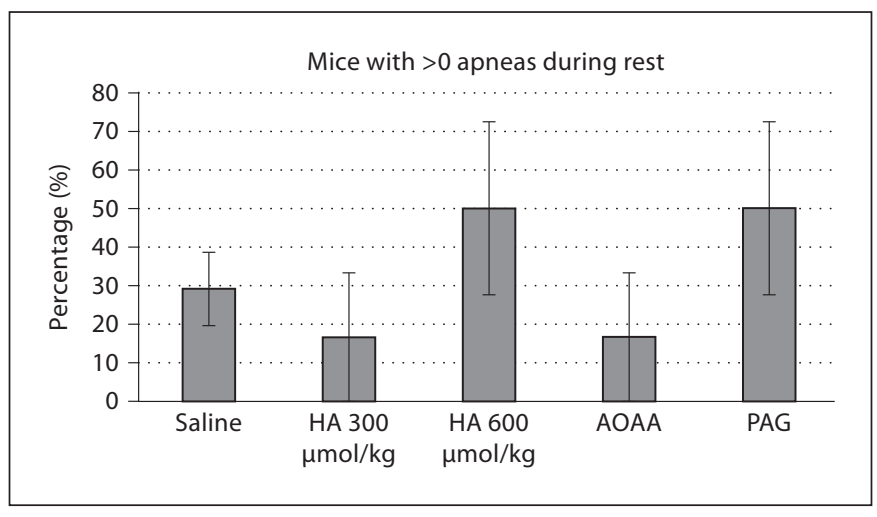

Fig. 4. Percentage of animals expressing $>0$ apneas. No significant differences from saline were found by $\mathrm{z}$ test for proportions.

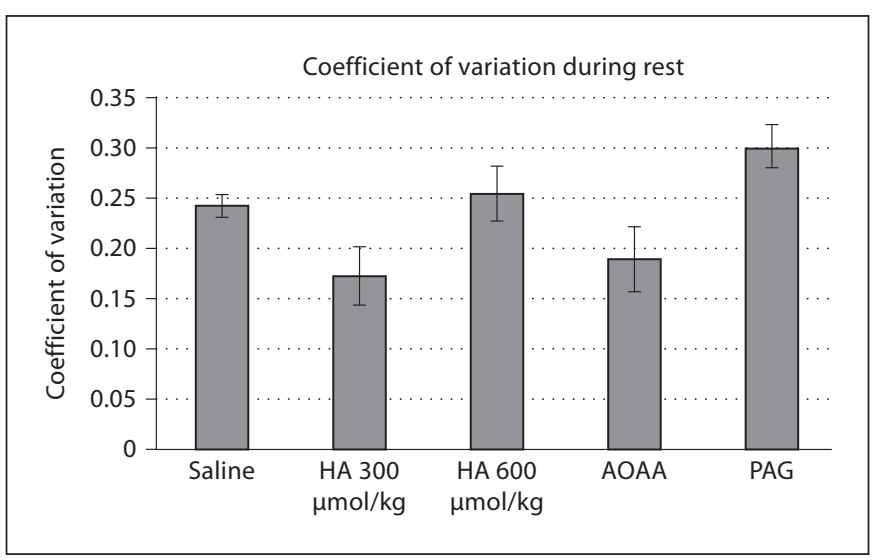

Fig. 5. Coefficient of variation for breath-to-breath $f$ at rest. No groups were found to significantly differ from saline by post hoc analysis.

The percentage of animals possessing one or more apneas during reoxygenation was significantly less than saline for HA $(600 \mu \mathrm{mol} / \mathrm{kg})$ and AOAA by $\mathrm{z}$ test for proportions (fig. 7).

Another marker of respiratory stability, the CV for breath-to-breath $f$, also varied as a function of administration group $(\mathrm{p}<0.01)$. The AOAA administration group demonstrated a lower $\mathrm{CV}$ for $f$ during reoxygenation (fig. 8).

\section{Temperature Effects}

When resting and postexposure rectal temperatures were compared by paired $t$ test, animals in each administration group experienced acute hypoxia-induced ana- 


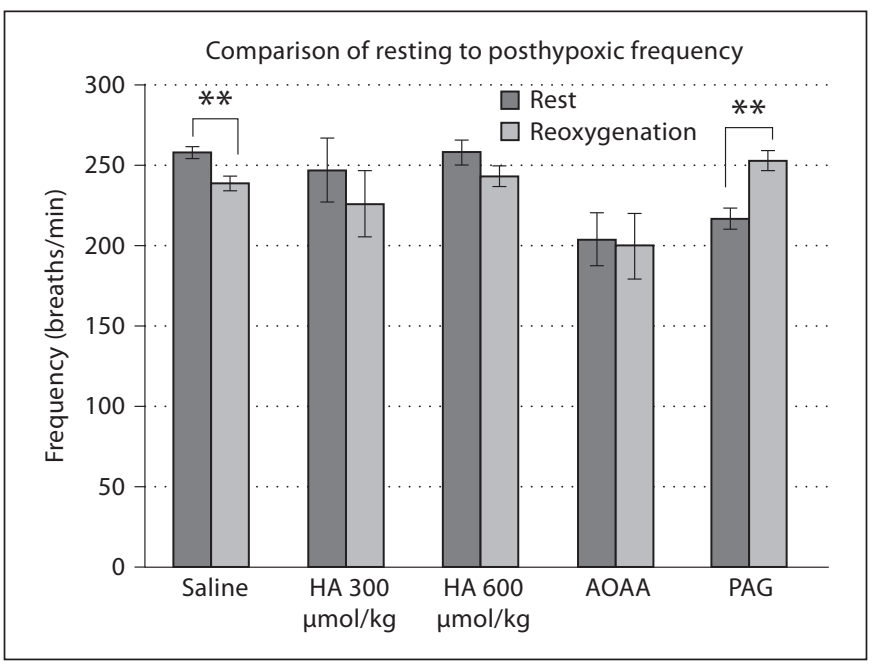

Fig. 6. Comparison of resting and post-hypoxic respiratory frequency. Significant differences within each group between rest and reoxygenation $f$ as determined by paired test are marked as follows: ${ }^{* *} \mathrm{p}<0.01$.

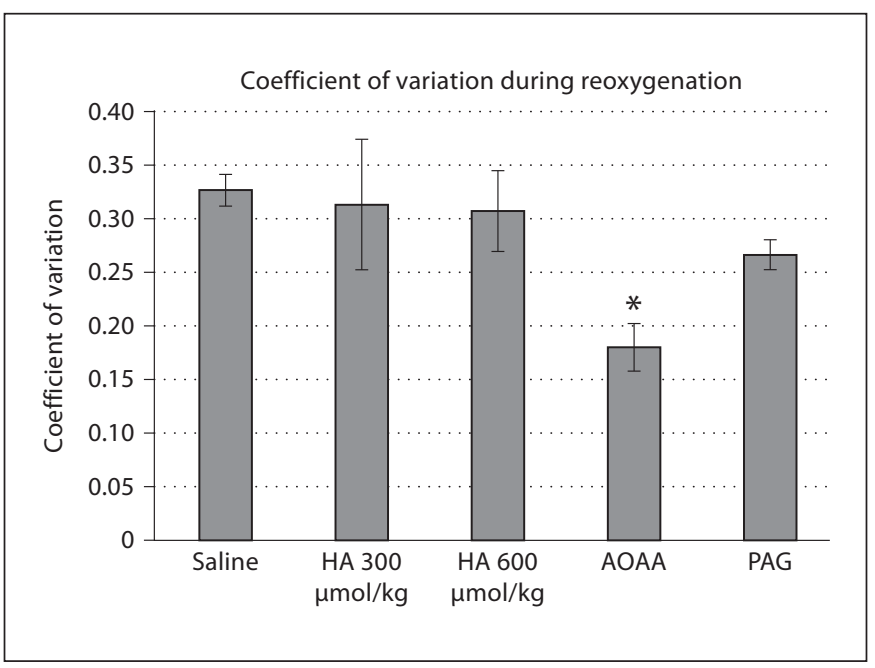

Fig. 8. Displayed is the coefficient of variation for respiratory frequency during the first minute of reoxygenation with saline and drug administrations. Significant differences from saline as determined by post hoc Dunnett's test are marked as follows: ${ }^{*} \mathrm{p}<0.01$.

pyrexia (saline, p $<0.001$; HA $300 \mu \mathrm{mol} / \mathrm{kg}$, p $<0.05$; HA $600 \mu \mathrm{mol} / \mathrm{kg}, \mathrm{p}<0.001 ;$ AOAA, $\mathrm{p}<0.001 ; \mathrm{PAG}, \mathrm{p}<0.05)$; however, the anapyrexia occurred to varying degrees and significant postexposure differences among groups existed $(\mathrm{p}<0.001)$. Significantly lower postexposure differences compared to saline existed for AOAA administra-

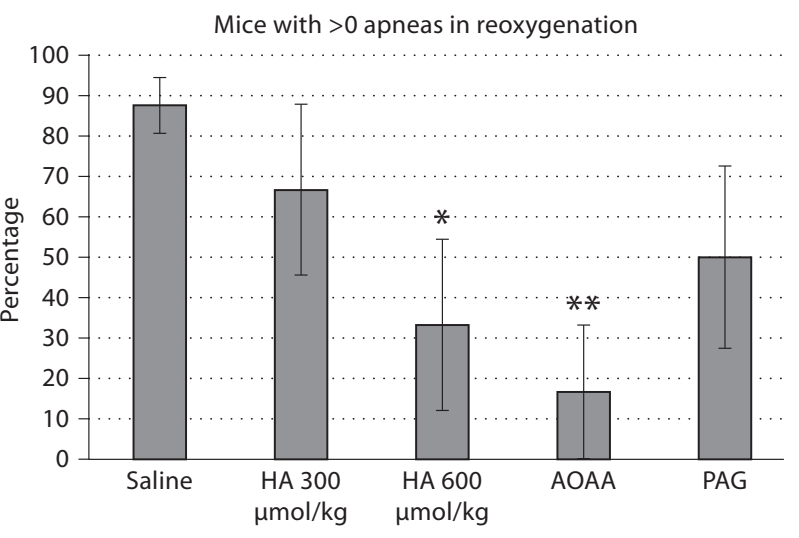

Fig. 7. Percentage of animals expressing $>0$ apneas. Significant differences compared to saline, as determined by $\mathrm{z}$ test for proportions, are marked as follows: ${ }^{*} \mathrm{p}<0.05,{ }^{* *} \mathrm{p}<0.01$.

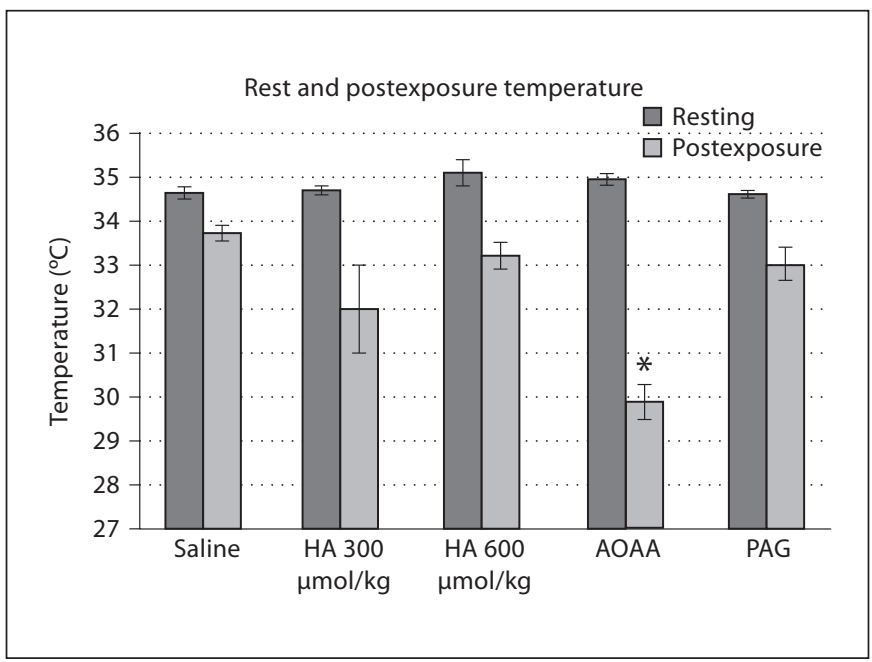

Fig. 9. Rectal temperature in ${ }^{\circ} \mathrm{C}$ for mice prior to acclimatization and following reoxygenation. Significant differences from saline for postexposure temperature, as found by post hoc Dunnett's test, are noted as follows: ${ }^{*} \mathrm{p}<0.05$.

tion. No pre-injection temperature differences among groups were found by ANOVA (fig. 9).

In contrast, without hypoxic stimulus, no differences were found by paired $t$ test in any administration group between rectal temperature prior to i.p. injection and rectal temperature $30 \mathrm{~min}$ following injection (note that the 
Fig. 10. Rectal temperatures prior to and following i.p. injection of saline or HSSI while animals remained at $21 \% \mathrm{O}_{2}, \mathrm{n}=3$ mice/group. ${ }^{* *} \mathrm{p}<0.01$ for difference from saline after i.p. injection by Dunnett's test.

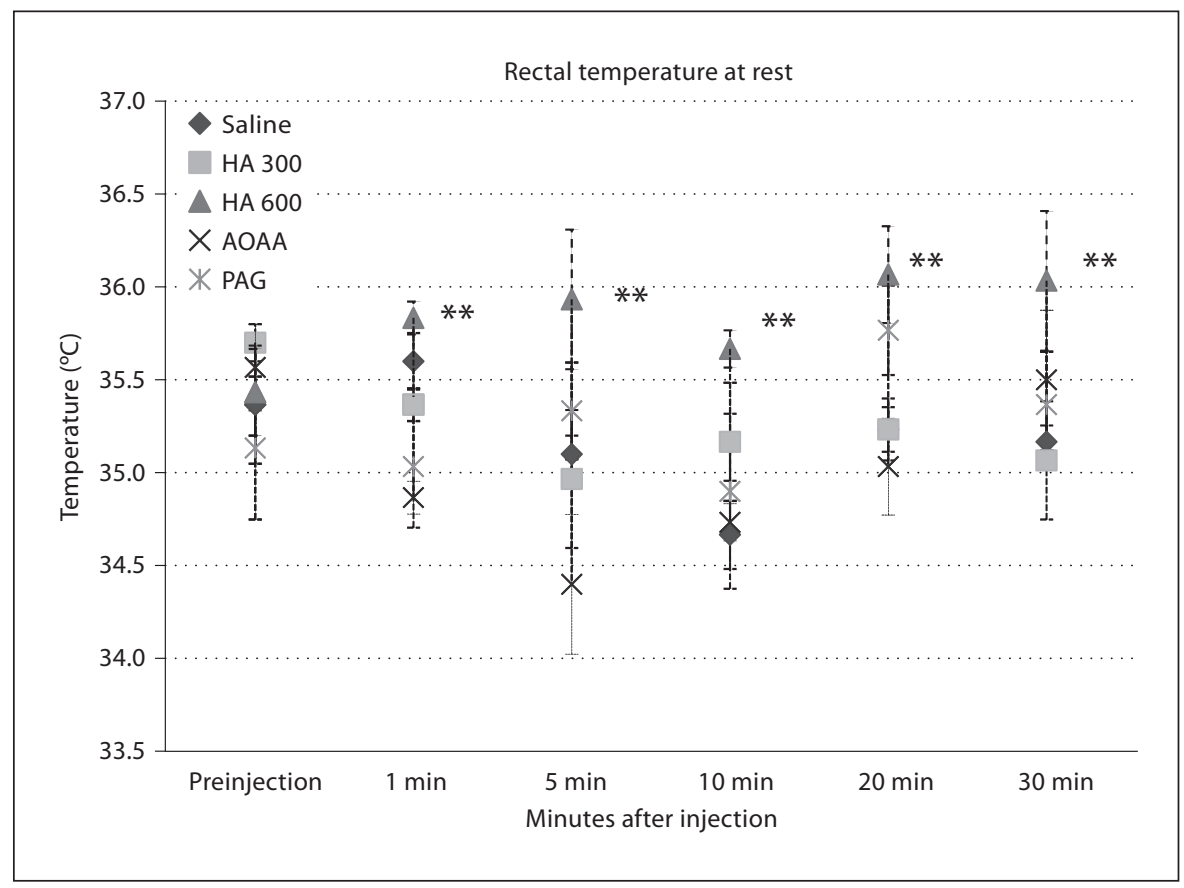

reoxygenation period ended $30 \mathrm{~min}$ following drug administration). No differences among groups were found by ANOVA at baseline $(\mathrm{p}=0.687)$ or at $30 \mathrm{~min}$ following injection ( $\mathrm{p}=0.152)$.

When all postinjection temperatures (not just those recorded at $30 \mathrm{~min}$ after injection) were compared to preinjection temperatures by ANOVA, no significant changes from baseline were observed. When postinjection temperature was compared among groups, significant differences existed $(p<0.001)$. Post hoc Dunnett's test revealed that the HA $(600 \mu \mathrm{mol} / \mathrm{kg})$ group demonstrated a slight but significantly higher mean postinjection temperature than saline (saline $35.2 \pm 0.10^{\circ} \mathrm{C}$, HA $600 \mu \mathrm{mol} / \mathrm{kg}$ $35.9 \pm 0.12^{\circ} \mathrm{C}$; fig. 10$)$.

\section{Discussion}

This study demonstrates that, compared to saline, administration of the HSSI HA and AOAA results in a decreased incidence of apnea in the C57BL/6J mouse strain during the acute posthypoxic period. This occurred despite some disparity among inhibitors in their effect on hypoxic response. Additionally, AOAA administration resulted in a reduced $\mathrm{CV}$ in reoxygenation $f$. Finally, STP, a promoting factor for respiratory stability [16], was observed in the PAG group.

$\mathrm{H}_{2} \mathrm{~S}$ Synthesis Inhibitors and Respiratory Stability
Consistent with previous reports, AOAA administration $(300 \mu \mathrm{mol} / \mathrm{kg})$ resulted in a blunted response to hypoxia, and acute (approx. $15 \mathrm{~min}$ ) PAG administration did not alter hypoxic responsiveness $[3,4]$. The current study does not demonstrate a decreased $\mathrm{V}_{\mathrm{E}}$ during hypoxia with the administration of HA $(300 \mu \mathrm{mol} / \mathrm{kg})$, as has been described previously [3]. This discrepancy is perhaps secondary to the limitation of whole body plethysmography in measuring $V_{T}$ depending on humidity and temperature differences between animal and chamber $[17,18]$. Furthermore, Kunming mice of either sex were tested by $\mathrm{Li}$ et al. [3], whereas male C57BL/6 6 mice are examined herein. Interestingly, $\mathrm{HA}$ administered at a dosage of $600 \mu \mathrm{mol} / \mathrm{kg}$ resulted in a trend towards an increased hypoxic response (fig. 2). To our knowledge, this is the first time that this dosage has been tested in vivo. The discrepant effect of HA on hypoxic responsiveness is interesting and could result from compensatory synthesis of $\mathrm{H}_{2} \mathrm{~S}$ by CSE enzymatic activity or effects of $\mathrm{HA}$ at this dosage on pathways not utilizing $\mathrm{H}_{2} \mathrm{~S}$.

Of interest, in this study and others $[3,4]$, the administration of HSSI such as AOAA, HA and PAG has resulted in decreased responses to hypoxia. One would expect that administration of gaseous $\mathrm{H}_{2} \mathrm{~S}$ would achieve the opposite result of those seen with HSSI. However, gaseous $\mathrm{H}_{2} \mathrm{~S}$ administration has also been found to reduce the ventilatory response to hypoxia [19]. These 
counterintuitive findings indicate that pharmacologic modulation of $\mathrm{H}_{2} \mathrm{~S}$ synthesis is complex, and further research is needed to elucidate the systemic effects of HSSI on $\mathrm{H}_{2} \mathrm{~S}$ levels at the loci of chemosensitivity and respiratory control.

Hypoxia-induced anapyrexia is the decrease in temperature noted when a mammal or bird is exposed to hypoxia [20], and it was noted in each group. Of interest, the animal group with a significantly diminished hypoxic $f$, $\mathrm{V}_{\mathrm{T}}$ and $\mathrm{V}_{\mathrm{E}}$ response compared to saline, AOAA, was the only group to experience a significantly more marked anapyrexia than saline. No temperature difference from saline was noted when AOAA was administered without hypoxic exposure. Therefore, it is likely that hypoxia-induced anapyrexia is responsible for the temperature differences between AOAA and saline.

Hypoxia-induced anapyrexia is thought to be caused by a change in hypothalamic set point [19], and it is possible that effects at the level of the hypthalamus contributed to both the hypoxic ventilatory response in the AOAA treatment group and the ability of the two systemically administered drugs to enhance hypoxia-induced anapyrexia.

The lack of a consistent effect of the HSSI on hypoxic response illustrates that the reduction in apneic activity among AOAA and HA is likely not solely due to a reduction in ventilatory overshoot-induced hypocapnia. This has previously been demonstrated as a potential etiology for recurrent apneas dependent on peripheral chemoreceptor function [21]. Instead, there may be interactions among peripheral and central mechanisms responsible for respiratory patterning of rate and depth.

An increase in posthypoxic stability, defined by a reduced $C V$, was observed with the use of CBS inhibitor AOAA, but not the CSE inhibitor PAG. Furthermore, decreased apneic activity was also only seen with the CBS inhibitors HA and AOAA. CBS is found in abundance in the brain [22], whereas little of CSE is primarily found peripherally with limited expression in the central nervous system [23]. Inhibition and activation of CBS have been found to decrease and increase the frequency of rhythmic meduallary respiratory activity, respectively [5]. At rest, no differences were found amongst the HSSI agents compared to saline in the number of animals expressing one or more apneas, but injection of the CBS inhibitor HA $(300 \mu \mathrm{mol} / \mathrm{kg})$ resulted in a trend towards increased stability. This finding suggests that the ability of CBS inhibitors to improve respiratory stability is more marked in the posthypoxic period as opposed to at rest.

\section{Limitations}

This study possesses several limitations. First, although this study demonstrates that HSSI agents can affect respiratory stability in the B6 mouse, the location of this systemic effect is unable to be determined by the current data. Second, the use of unrestrained whole body plethysmography is also limiting, because, as stated above, this method tends to accurately record $f$, but not $\mathrm{V}_{\mathrm{T}}[17,18]$. Third, although our study does make use of postexposure rectal temperature recordings, the lack of continuous measurements during the challenges hampers our ability to make more conclusive remarks on hypoxia-induced anapyrexia between the various administrations; manipulation of the animals during plethysmography testing was avoided so as not to impact our primary outcome, posthypoxic ventilatory behavior. Fourth, our use of only one strain of mouse limits the ability to generalize our results to other strains or species. Finally, the HSSI agents used have poor selectivity for CBS and CSE [24], but unfortunately selective agents are not currently available and, like other studies examining $\mathrm{H}_{2} \mathrm{~S}$ inhibition $[3,4,25]$, multiple inhibitors are used in the current investigation to mitigate this lack of selectivity.

\section{Conclusion and Future Directions}

This study demonstrates the in vivo ability of HSSIs targeting different the CBS enzymatic pathways to result in increased ventilatory stability in the post-hypoxic period. Furthermore, CBS, but not CSE, inhibition results in increased ventilatory stability at rest. While the manner and location(s) along the respiratory control axis at which these effects take place are unknown, such a model gives insight into the coupling of chemosensation and stability that may lead to better design of pharmacologic agents to target clinical disorders of ventilatory control.

\section{Acknowledgements}

We would like to thank Mr. Kevin Knaus of the Lacek Group for his assistance in computer programming. This study was supported by the VA Research Service and by the NIH-NINDS (NS O52452). 


\section{References}

1 Kimura $\mathrm{H}$ : Hydrogen sulfide: its production and functions. Exp Physiol 2011.

2 Mustafa AK, Gadalla MM, Snyder SH: Signaling by gasotransmitters. Sci Signal 2009; 2:re2.

-3 Li Q, Sun B, Wang X, Jin Z, Zhou Y, Dong L, Jiang LH, Rong W: A crucial role for hydrogen sulfide in oxygen sensing via modulating large conductance calcium-activated potassium channels. Antioxid Redox Signal 2010; 12:1179-1189.

-4 Peng YJ, Nanduri J, Raghuraman G, Souvannakitti D, Gadalla MM, Kumar GK, Snyder SH, Prabhakar NR: $\mathrm{H}_{2} \mathrm{~S}$ mediates $\mathrm{O}_{2}$ sensing in the carotid body. Proc Natl Acad Sci USA 2010;107:10719-10724.

- $5 \mathrm{Hu}$ H, Shi Y, Chen Q, Yang W, Zhou H, Chen L, Tang Y, Zheng Y: Endogenous hydrogen sulfide is involved in regulation of respiration in medullary slice of neonatal rats. Neuroscience 2008;156:1074-1082.

-6 Eckert DJ, Jordan AS, Merchia P, Malhotra A: Central sleep apnea: Pathophysiology and treatment. Chest 2007;131:595-607.

-7 Han F, Subramanian S, Dick TE, Dreshaj IA, Strohl KP: Ventilatory behavior after hypoxia in c57bl/6j and a/j mice. J Appl Physiol 2001;91:1962-1970.

$\checkmark 8$ Yamauchi M, Dostal J, Kimura H, Strohl KP: Effects of buspirone on posthypoxic ventilatory behavior in the $\mathrm{c} 57 \mathrm{bl} / 6 \mathrm{j}$ and $\mathrm{a} / \mathrm{j}$ mouse strains. J Appl Physiol 2008;105:518-526.

-9 Yamauchi M, Dostal J, Strohl KP: Acetazolamide protects against posthypoxic unstable breathing in the c57bl/6j mouse. J Appl Physiol 2007;103:1263-1268.
10 Chapman KR, Bruce EN, Gothe B, Cherniack NS: Possible mechanisms of periodic breathing during sleep. J Appl Physiol 1988; 64:1000-1008

11 Verbraecken JA, De Backer WA: Upper airway mechanics. Respiration 2009;78:121133.

12 Han F, Subramanian S, Price ER, Nadeau J, Strohl KP: Periodic breathing in the mouse. J Appl Physiol 2002;92:1133-1140.

13 Cummings KJ, Frappell PB: Breath-tobreath hypercapnic response in neonatal rats: Temperature dependency of the chemoreflexes and potential implications for breathing stability. Am J Physiol Regul Integr Comp Physiol 2009;297:R124-R134.

14 Yamauchi M, Kimura H, Strohl KP: Mouse models of apnea: Strain differences in apnea expression and its pharmacologic and genetic modification. Adv Exp Med Biol 2010;669: 303-307.

15 Yamauchi M, Ocak H, Dostal J, Jacono FJ, Loparo KA, Strohl KP: Post-sigh breathing behavior and spontaneous pauses in the c57bl/6j (b6) mouse. Respir Physiol Neurobiol 2008;162:117-125.

16 Georgopoulus D, Giannouli E, Tsara V, Argiropoulou P, Patakas D, Anthonisen NR: Respiratory short-term poststimulus potentiation (after-discharge) in patients with obstructive sleep apnea. Am Rev Respir Dis 1992;146:1250-1255.

17 Chaui-Berlinck JG, Bicudo JE: The signal in total-body plethysmography: Errors due to adiabatic-isothermic difference. Respir Physiol 1998;113:259-270.
18 Jacky JP: Barometric measurement of tidal volume: effects of pattern and nasal temperature. J Appl Physiol 1980;49:319-325.

19 Haouzi P, Bell HJ, Notet V, Bihain B: Comparison of the metabolic and ventilatory response to hypoxia and $\mathrm{H}_{2} \mathrm{~S}$ in unsedated mice and rats. Respir Physiol Neurobiol 2009; 167:316-322.

20 Wood SC: Interactions between hypoxia and hypothermia. Annu Rev Physiol 1991;53:7185.

21 Nakayama H, Smith CA, Rodman JR, Skatrud JB, Dempsey JA: Carotid body denervation eliminates apnea in response to transient hypocapnia. J Appl Physiol 2003;94: 155-164.

22 Abe K, Kimura H: The possible role of hydrogen sulfide as an endogenous neuromodulator. J Neurosci 1996;16:1066-1071.

23 Yang G, Wu L, Jiang B, Yang W, Qi J, Cao K, Meng Q, Mustafa AK, Mu W, Zhang S, Snyder $\mathrm{SH}$, Wang $\mathrm{R}$ : $\mathrm{H}_{2} \mathrm{~S}$ as a physiologic vasorelaxant: Hypertension in mice with deletion of cystathionine gamma-lyase. Science 2008 322:587-590.

24 Caliendo G, Cirino G, Santagada V, Wallace JL: Synthesis and biological effects of hydrogen sulfide (h2s): Development of $\mathrm{H}_{2} \mathrm{~S}$-releasing drugs as pharmaceuticals. J Med Chem 2010;53:6275-6286.

-25 Leffler CW, Parfenova H, Basuroy S, Jaggar $\mathrm{JH}$, Umstot ES, Fedinec AL: Hydrogen sulfide and cerebral microvascular tone in newborn pigs. Am J Physiol Heart Circ Physiol 2011;300:H440-H447. 